\title{
Sensing the Classroom: Improving Awareness and Self-Awareness of Students in Backstage
}

\author{
Alexander Pohl, François Bry, Jeannette Schwarz, and Marlene Gottstein \\ Institute for Informatics \\ University of Munich \\ Munich, Germany \\ http://pms.ifi.lmu.de
}

\begin{abstract}
Backstage is a digital backchannel that is carefully designed for the use in large lecture classes. The goal of Backstage is to support social and active learning in a mainly impersonal and passive learning setting. In classes with a large and anonymous audience, passivity can be a cause of lowered awareness. This paper introduces Backstage and discusses its range of functions in the light of how it contributes to awareness. It furthermore introduces newly conceived concepts by which information are collected and properly displayed in order to help both students and lecturer to gain insight about who is around, what are the kinds of activities the community is engaged in, and what matters in the lecture.
\end{abstract}

Extended Classroom, Digital Backchannel, Awareness, Participation

\section{INTRODUCTION}

In the context of digital media, backchannels refer to $\mathrm{CMC}^{1}$ software used to establish publicly visible, non-disruptive communication among audience members alongside (and synchronously to) the presenter's discourse (e.g. [1-3]). Paramount examples of CMC software for backchannels are $\mathrm{IRCs}^{2}$ and, recently, microblogging platforms like Twitter ${ }^{3}$. While initially backchannels were used in industrial conferences and attracted much attention, efforts have been invested to also use backchannels in lecture classes (e.g. [4-6]). The pivotal idea is that the use of backchannels may contribute to diminishing the anonymity and passivity of students in large lecture classes. Backchannels offer opportunities to actively engage in the lecture and thus might help to mitigate the adverse effects of the impersonal and generally passive environment of a lecture hall.

In large lectures usually less information is shared among the audience as [7] states is the case for impersonal environments. However, awareness of others is a critical factor in the coordination of group activities [8], and to certain degrees relies on sharing of information. In large lecture classes, neither the students nor the lecturer are sufficiently provided with information that facilitates a more personal, (re-) active and social involvement. Even more, a rash use of general-purpose communication tools as backchannels can have counterproductive effects in lectures. For example, they

\footnotetext{
${ }^{1}$ Computer-Mediated Communication

${ }^{2}$ Internet Relay Chats

${ }^{3}$ http://twitter.com
}

generally fail to support the presenter in staying connected with the audience on the backchannel ${ }^{4}$. Neither do they foster the kind of communication beneficial for learning. For these very reasons, the backchannel Backstage has been designed specifically for the use in large lecture classes [9-11]. The purpose of Backstage is to evoke and mediate social actions within the class and to activate students in way conducive for learning. In this way, Backstage makes information upon which the classroom awareness can be improved.

Though being a genuine source of awareness information, an active (and therefore rather cluttered) backchannel does not immediately reveal the awareness information sought. Thus, it is required that the backchannel discourse be adeptly processed and displayed in order to provide a higher-level view not only easier to comprehend but also more significant to the classroom community. For example, students can find out, if they ask questions, or respond to questions, more often than their peers (i.e. the average). The lecturer might particularly be interested in brief feedback relevant to her teaching and in comments worth responding to.

Usually, immediate awareness-related information, e.g. the users who are currently online, can be provided on a backchannel without much ado. Yet, awareness information may also emerge from the backchannel discourse. Filtering and aggregation play fundamental roles in the extraction and the emphasis of awareness-related information. Filtering reduces the information load by ignoring (temporarily) irrelevant items. For example in [12] two kinds of filtering are distinguished, among others. Cognitive filtering accounts for information solely based on contents (e.g. filtering the backchannel by keywords or by category such as question, answer, etc.). Social filtering considers the interrelationships of the individuals in the community to assess the relevance of information (e.g. the role or the reputation of the origin, or recommendations by community members). The two kinds of filtering complement each other. Aggregation reduces information load by generating (genuinely) new information that abstracts the underlying information to a single item. For example, the backchannel comments of a user can be abstracted to an aggregate value that shows her backchannel activity. Likewise, the activities of all users in the lecture can be aggregated to show the overall backchannel activity in the lecture.

${ }^{4}$ e.g., www.zephoria.org/thoughts/archives/2009/11/24/spectacle_at_we.html 
In this article we present concepts for Backstage, which aim to support the awareness of the activities during the lecture to unfold. This presentation briefly reviews already existing functionalities of Backstage in the light of awareness and introduces refinements and further concepts yet to be realized.

\section{THE ROLE OF AWARENESS}

Awareness describes "an understanding of the activities of others, which provides a context for your own activity" [8]. Usually in large lecture classes the students as well as the lecturer are seldom fully aware of the other's thoughts, concerning the lecture material. Students who have questions may thus hesitate to ask because they think they are the only ones who have problems in understanding the topic. Having awareness of the questions or thoughts of other students might lower the doubts and therefore lead to an increase of participation. Seeing that others have problems as well, noticing other students with the same remarks or helping others could create a common ground and lower the social distance between the students and between the audience and the lecturer.

In fact, research has shown that awareness has a positive effect on communication and interaction while helping the students to develop a shared sense of community [13], which is crucial to learning and interaction within the Computer Mediated Discourse. Hence, it is critical to find a way to encourage students to participate in the classroom, leading to disclosure of information, which is an important part of awareness [14].

One can distinguish between passive [13] and active, i.e. intentionally and deliberately enriched, awareness [15]. The former refers to awareness based upon information that is automatically gathered by the system, then correlated and distributed to the other users. Contrary to active awareness, passive awareness does, at first glance, not require an active disclosure of information by others. It focuses on information that emerges unintentionally, e.g. by simply attending a lecture. Active awareness is defined as including "information that people actively share with others." It is created by intentional communication, which occurs when "people deliberately direct the attention of others in order to create awareness" [16].

However, in [16] it is argued that the term 'awareness' has been used in contradictory ways and that it is in many cases unclear how awareness comes to existence. For example, the distinction between a passive and active awareness is questioned. Rather, actors modulate their activities and determine the appropriate degree of obtrusiveness in order to be perceived by others. Awareness "is not the product of passively acquired 'information' but is a characterization of some highly active and highly skilled practices" (ibid., p. 292). However, it notes that actors somehow monitor the activities of others to ascertain the state, progress and direction of these activities.

The impact of social awareness in collaborative e-learning has been investigated in [17]. It reports on the integration of awareness tools in the e-learning platform Moodle and on the assessment of the tools' effects on participation. The results suggest that social awareness can contribute to an improved quality of active participation.

Before proceeding with the presentation of the awareness concepts it is reasonable to present an overview of the different kinds of awareness information, which are given in the Table 1.

TABLE 1. The table shows the kinds of awareness information sought together with the respective concepts for Backstage.

\begin{tabular}{|l|l|l|}
\hline $\begin{array}{l}\text { Type of } \\
\text { Awareness } \\
\text { Information }\end{array}$ & $\begin{array}{l}\text { Awareness Concepts in } \\
\text { Backstage }\end{array}$ & $\begin{array}{l}\text { Dependency } \\
\text { on the } \\
\text { Progress of } \\
\text { the Lecture } \\
\text { Discourse }\end{array}$ \\
\hline Social & $\begin{array}{l}\text { User presence } \\
\text { Followership } \\
\text { Activity aggregator } \\
\text { Reputation of users }\end{array}$ & Independent \\
\hline Workspace & $\begin{array}{l}\text { Categorical distribution of posts } \\
\text { Explicit notifications } \\
\text { Rating of posts }\end{array}$ & Independent \\
\cline { 2 - 3 } & $\begin{array}{l}\text { Ranking of posts } \\
\text { Annotation of slides } \\
\text { Filter boxes }\end{array}$ & Dependent \\
\hline
\end{tabular}

We are particularly interested in gathering information related to social and workspace awareness. These terms are adopted from [18]. Therein, social awareness is introduced as the consciousness of the social interrelations within the community. Among others, social awareness deals with the questions "What should I expect from other members of this group?" and "How will I interact with this group?" (ibid., p. 2). Thus, we understand social awareness information mainly as user- and community-related. Workspace awareness deals with the questions "What are they [i.e. the other group members] doing?", "What have they already done?", "Where are they", and "How can I help other students to complete the project?" (ibid., p. 2). We consider workspace awareness in a wider sense as content-related.

Another aspect worth mentioning is that some pieces of awareness information depend on the progress of the lecture discourse, since they are based on different backchannel states as the lecture proceeds, e.g. the annotation of slides. Other pieces of awareness information, however, change independently from the lecture progress and thus are not innately dependent on the lecture discourse (cf. Table 1). Consequently, the progress of the lecture needs to be captured in Backstage, which is currently achieved by navigating in the slides: when the user selects another slide at her dashboard, the dependent awareness information is discarded and determined anew. The concept of filter boxes presented in the course of this paper, however, generalises the capturing of lecture progress in Backstage by means of location filters (cf. Section C.5).

\section{A SHORT INTRODUCTION TO BACKSTAGE}

The dashboard, i.e. the user interface provided during the lecture, consists of three parts. The first part comprises a microblogging platform by which students can share their 
thoughts and comments on the lecture Fig. 1 A). A key characteristic of microblogs is the brevity of posts comprising only a few words. Besides public communication, posts can also be private or anonymous, as specified by predefined keywords at the beginning of the posts. Private posts are visible only to those users that are specified by the sender in the post. They can be used to obtain social support by a selected group of users, prior to making the post public. Anonymous messages may help to initiate the backchannel discourse, e.g. at the beginning of a teaching term. Though, private and anonymous communication bears the risks of group dissociations and abuse. Thus, the lecturer can enable or disable these modes of communication. Furthermore, students may also take personal notes on the lecture that are not published to others. Students may rate microblog posts using a simple rating scheme: A positive rating expresses approval and a negative rating expresses rejection. Backstage requires that the microblog posts be assigned to categories predefined by the lecturer, e.g. Question, Answer, and Remark. Categorization can be a first step to counteract off-topic messages.

The second part comprises the slides to convey a context for the backchannel, i.e. the lecture discourse (Fig. $1 \mathrm{~B})$. The backchannel posts need to refer to a slide. Stated differently, slides are annotated by the backchannel posts. Therefore, in the course of writing the post an icon depicting the post's category is dropped onto that place of a slide to which the posts refers (Fig. 1 D) [19]. Both the predefined categories as well as the iconic-drag and drop approach to annotating slides implicitly convey to the students the communication sought on Backstage.

The third part comprises a virtual representation of the lecturer (Fig. $1 \mathrm{C}$ ), in case of the students' dashboards, and provides further space for awareness components, many of which are presented in this paper (e.g. the Activity Aggregator, or the categorical overview of posts).

Besides the audience's engagement in the backchannel discourse, the lecturer may also call for participation by means of quizzes, which are reminiscent to Audience Response Systems or Classroom Response Systems (e.g. [20-22]). These have been shown to be very successful means to promoting participation of the audience [20]. The conduct of quizzes may not only assess the students' previous knowledge or opinions about the lecture's topic but also provides opportunities to break up the lecturer's discourse into smaller chunks. Quizzes may re-activate students and promote participation, for example, by combining the answering of quizzes with short discussions on the backchannel (cf. [23]).

\section{Supporting AwARENESS With BACKSTAGE}

The Table 1 shows the concepts in Backstage conceived to make the respective awareness information available. It should be noted that the concepts are not addressed to both students and lecturer alike. In the presentation of the concepts, however, we make clear which user we aim to address.

\section{A. Social Awareness Information in Backstage}

1) A User's Presence in the Backchannel

Backstage distinguishes between three kinds of user presence: online, offline, and busy. While the first two have their obvious meanings, the latter is a limited form of online presence: being "busy" conveys to the others that the student is, in fact, online but wants to focus on the lecture discourse and therefore is not participating in the backchannel.

It should be noted that on Backstage the state of presence also determines the range of functions available at the student's dashboard. While an online student is equipped with the usual dashboard (cf. Fig. 1), a student in busy-mode is provided with just the slides and the quizzes being conducted by the lecturer. The microblog timeline (Fig. $1 \mathrm{~A}$ ), the respective annotations on the slides (Fig. 1 D), and other awareness components (Fig. $1 \mathrm{C})$ are not available. In a sense, the dashboard is degraded to merely an extension of the frontchannel and thus aims to support the student in following the lecture discourse in the best possible manner. In future versions of Backstage we plan to provide microblogging to users also in busy-mode, yet solely for the purpose of taking personal notes.

As a central object of interaction, the backchannel posts inform users about the presence of their respective authors. Though, this information needs to be explicitly requested by moving the mouse cursor over the post, in order to reduce distraction and to keep the dashboards calm.

\section{2) Establishing Followership between Students}

A student might want to be particularly aware of some peers whose contributions she finds valuable. That is, those peers should be given more significance at her dashboard than others. The idea is thus to allow the users of Backstage to establish follower-relationships. Following a peer leads to an emphasis of the peer's contributions at the user's dashboard. The posts of followed users are visually highlighted at the dashboard so as to stand out from the remaining backchannel discourse. The follower-relationship is also used in the comparison between a student's and the audience's activities in the Activity Aggregator that is presented below (Fig. 3). 


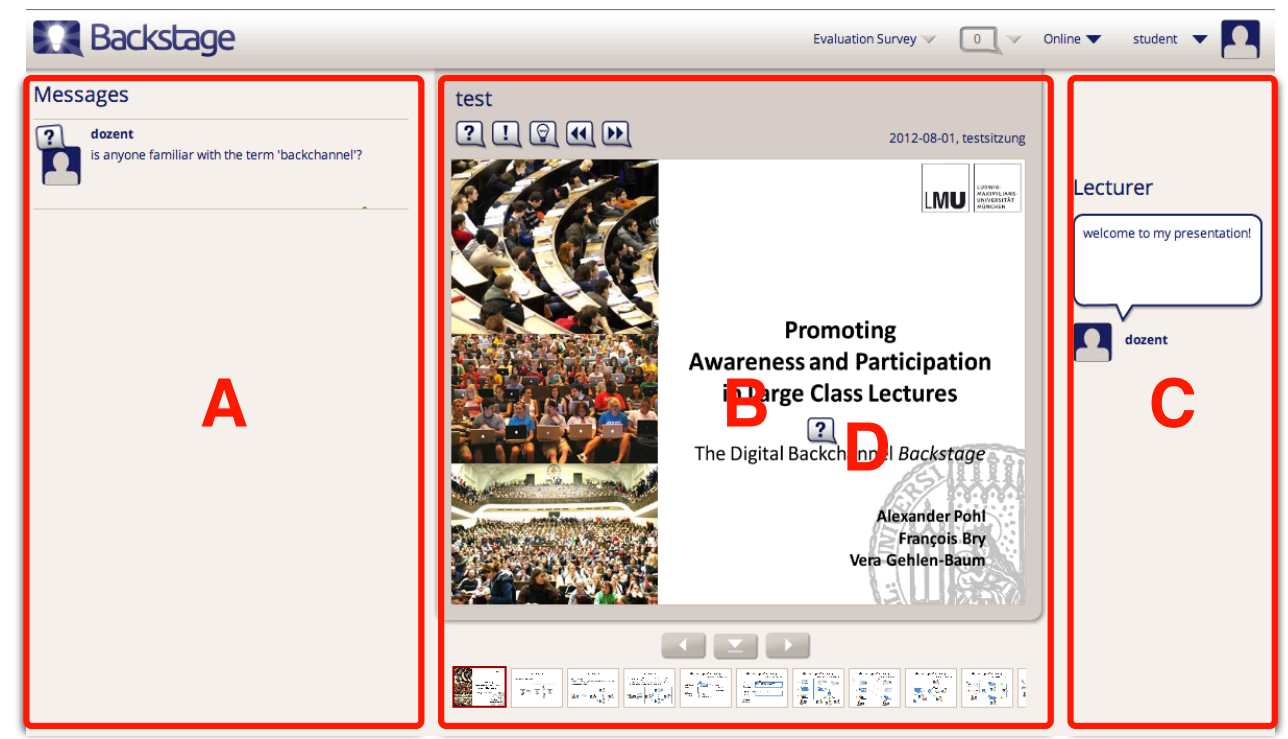

Figure 1 The student's dashboard consists of three columns. A) The leftmost column shows the backchannel discourse related to the current slide. B) The column at the centre provides the lecture context for the backchannel by showing the slides. Posts need to refer to a certain location of a slide, i.e. they annotate slides. The annotation that results from the post is marked by D. C) The rightmost column is mostly reserved for presenting the lecturer (i.e. showing her avatar, her username, and a statement regarding the lecture) and for further awareness components.

A student might decide for various reasons to follow another student. It might be because the two are friends, or because she finds the other student's contributions valuable. Additionally, it is also conceivable to recommend peers to her. A recommendation system could nominate peers interesting to follow on the basis of the students' profiles and backchannel activities. For example, the recommendations could be made upon similar learning progress. Alternatively, students who tend to adopt controversial positions in discussions could be matched with the intention to improve their arguing skills or to parlay their knowledge on a given subject.

It should be mentioned that the term 'follower' is adopted from Twitter, where following another user results in the subscription of the followed user's posts. As a consequence the posts of the followed users are displayed at the follower's timeline in addition to her own. Furthermore, a followership between Twitter users results in a community of users that are interested in similar topics. However, on Backstage the notion of following is different. Following peers on Backstage is not targeted at the building of isolated sub-groups, as is the case in Twitter. Instead, followership aims at reducing the information load that might come up because of tracking all peers equally, especially when the audience is large. However, followerrelationships might help students to coordinate learning activities outside the lecture hall, e.g. forming learning groups and finding appropriate learning groups to join.

3) Displaying Degree of Involvment by the Activity Aggregator for Students

The Activity Aggregator is a concept that aims to supply the student with comprehensible information on the activities of hers and of peers, visualized in a concise way. We consider two versions: a lean version that is available during the lecture and an extended version for reworking after the lecture. The lean version displays the aggregated information on the student's activity, i.e. her involvement in the backchannel discourse, and the average ratings her posts received compared to the average. Figure 2 shows a prototype of the user interface of the lean version.

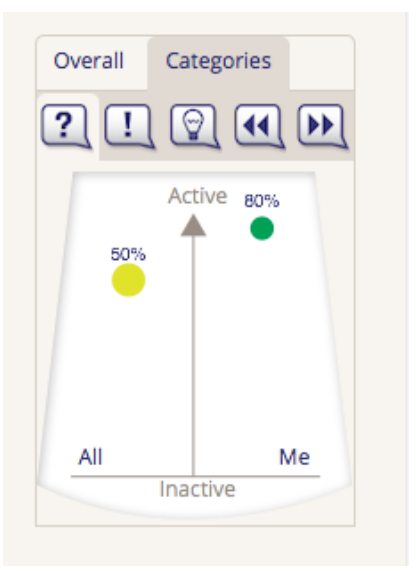

Figure 2 The lean version of the Activity Aggregator (concept drawing) shows the activity of a student compared to the average activity in the class in the contour of a lecture hall. The colour of the disc encodes the positive ratings received (from green over yellow to red in decreasing order)

The aggregator shows the activity of both the student and the audience within the contour of a lecture hall. Activity thereby comprises writing and rating of messages. The more active the student is on the backchannel the rather her disc is displayed on top. The size and of the disc and the percentage figure that labels the disc serve to represent the current average of ratings the student's posts received. The colour encodes the number of positive ratings (from green over yellow to red in decreasing order). For a more detailed overview, the student's activity can be filtered in regard to the predefined post categories. This allows her to figure out if, for 


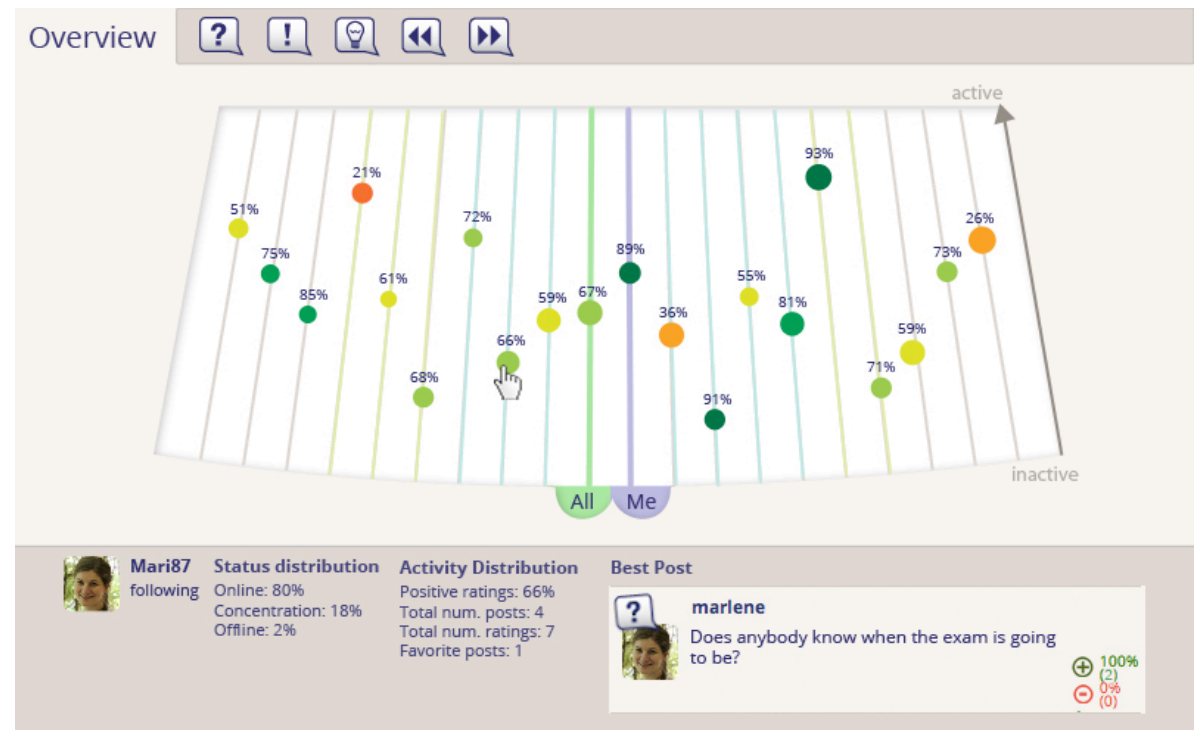

Figure 3 The extended version of the Activity Aggregator (concept drawing) shows the activities of the student (centre left, green line, labelled with 'Me'), the average activity (centre right, purple line, labelled with 'All') flanked by followed students (discs on the blue lines), other students who disclose personrelated information (yellow line), and students who remain anonymous (grey lines). Below the activity graph, the Aggregator shows further information related to a user when moving the mouse cursor over a disc.

instance, she is more committed to asking or to answering questions on the backchannel than the average.

When reworking the lecture the student is able to pay more attention to the Activity Aggregator. Since we do not have to account for distraction issues that might be relevant during lectures we may provide more detailed information by the Activity Aggregator. For example, students might profit from more personalized information regarding the activity of the audience. In this case it might be more useful to compare a student's backchannel activity to that of a decent number of other students, rather than, or in addition to, the average activity. We account for this in the extended version of the Activity Aggregator shown in Figure 3.

The activities and rating are displayed in the same manner as in the lean version, by using the vertical axis for the display of the activity value and the disc sizes for the rating values. In addition to plotting the two activities of the average and the current student, however, the extended version provides a decent number of further slots. At the centre of the activity graph the disc depicting the current student's activity can be found next to that of the average, which are flanked by the activities of further students. It is reasonable to fill available slots primarily with peers being followed, since they are explicitly selected by and thus of particular interest to the student. If the number of peers being followed is smaller than the number of slots available, the remaining slots may be filled with peers that are not being followed by the student. Likewise, if more peers are followed than there are slots available then the followed peers for the Activity Aggregator might be selected by some procedure. The peers that are associated to the slots might either be selected by random or by matching certain criteria such as similarity of the activity profiles.

The vertical lines in the activity graph are coloured to help the student recognize the different kinds of information the discs depict. In the prototype shown above, the green line at the centre indicates the average value of all students, the purple line highlights the current student, the blue lines highlight the students being followed, and the yellow and grey lines highlight randomly selected students not being followed. The grey lines furthermore hint at students who chose in their privacy settings to not expose any of their user-related information, such as their usernames; the control about what kind of information is displayed at the Activity Aggregator stays with the student. The Activity Aggregator also shows a navigation panel on top that allows the student the selection of a post category according to which the activity overview is filtered.

Further information about a peer may be displayed below the activity graph. Moving the mouse cursor over a disc yields further information about the respective student, e.g. her username, her current presence in the backchannel, the percentage of positive ratings her posts received, the number of posts she wrote in total, the total number of ratings her posts received, the posts that have been favoured by peers, and her best rated post of the session or lecture. However, as already mentioned, the students should be able to control the information published about them by the Activity Aggregator.

\section{4) Reputation of Users}

One of the goals of Backstage is to foster collaboration between students. The possibility for group members to acquire reputation has thereby shown to be a very effective incentive to contribute. Collaboration is an instance of reciprocity within a learning community. As political scientist Elinor Ostrom has phrased it, "When many individuals use reciprocity, there is an incentive to acquire reputation for keeping promises and performing actions with short-term costs but long-term net benefits" ([24], p.12). For this reason, students should be able to acquire reputation on Backstage. From the viewpoint of awareness, reputation of community members would also provide a partial answer to what can be expected from other community members and thus contributes 
to social awareness (cf. [18]). On Backstage, users would acquire reputation by writing posts useful to others appraised by respective ratings. Defining reputation on the basis of ratings of posts makes sense, since we consider the lecture class mainly as a work community.

In the Awareness Aggregator the ratings of a user's posts is aggregated with regard to the post categories. Thus, determining the reputation of a user with regard to the post categories might as well be worth considering. In so doing, the user can easily obtain insights into which kind of backchannel activity is most appreciated by her peers. The overall user's reputation is then obtained by aggregating her reputations obtained for each category.

\section{B. Concepts to Collect Workspace Awareness Information}

1) Categorical Distribution of Posts as an Indicator for the Prevailing Backchannel Discourse

Since backchannel posts need to be assigned to categories, it is possible to determine how the backchannel posts distribute to these categories. The lecturer can thus be provided with a concise overview of the prevailing kind of backchannel discourse in real-time. She can easily find out whether the students mainly post questions hinting her at potential (or expected) problems in following the lecture and react upon it. The Figure 4 shows the topical distribution of posts.

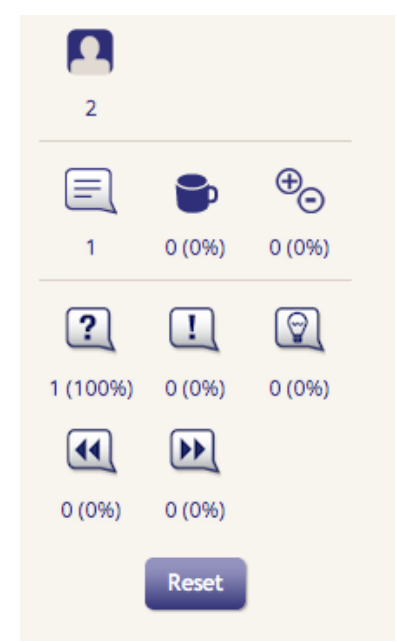

Figure 4 The categorical overview shows the lecturer how the posts distribute over the categories. Additionally, it provides the lecturer with the information on how many users have signed into the lecture session (figure at the top).

The categorical distribution window considers the backchannel discourse disregarding the change of slides. Rather, if the lecturer has acknowledged the distribution, and maybe commented on it, she may reset the overview explicitly. If the component was reset on every slide change it might be the case that, especially in times of lower backchannel activities, the awareness information would be discarded too quickly and thus fail to provide useful insights. For example, the lecturer might want to be aware of a rush of questions notwithstanding that they were raised on the previous slides.
2) Explicit Notification of Activities Related to a User's Posts

Creating awareness includes helping users to be aware of what their peers are doing and how they interact with one's own contributions, e.g. how often and which kinds of rating a post received. It might also be interesting to know if one's post has been forwarded to the lecturer's ranking. Furthermore, the users would like to be notified if the lecturer, as an outstanding authority of the community, gave a positive rating. A system that refrains from providing such information would miss a chance to keep the students engaged by ignoring that source of awareness information. Therefore, we propose the use of a notification system that is supposed to inform the student unobtrusively if anything "new" has happened to her posts. A student could be notified if, one of her posts is being rated, responded to in the backchannel, or forwarded to the lecturer's ranking of posts.

An objection against such notification system might be the distraction it introduces. However, as mentioned in the Section II any source for active awareness has a certain level of obtrusiveness. However, holding the interface simple and as unobtrusive as possible can help reducing distraction. The use of signal colours (e.g. red) or high-contrast combinations of colours should be avoided. Instead, the notification should keep itself in the periphery of the user's attention.

Notifications can contribute to a better use of Backstage. For example, a student who is waiting for a reply, that could enhance her understanding, would be better off waiting for a notification while following the lecture instead of permanently checking the slide where she placed her question until the answer finally appears. Additionally, the notifications provide immediate feedback, which is important for creating social presence. If a user still has the feeling of being distracted too much, she can switch her dashboard to busy-mode in which the notification system is disabled. Yet it might also make sense to allow the user to selectively enable or disable the notification system in her dashboard settings.

3) Rating and Ranking of Posts as Means to Estimate Relevance

Rating of posts not only serves to assess the relevance of a post with regard to the lecture. It also provides the information that peers have acknowledged the post. A positive rating suggests that a post is considered relevant. In case of posts that call for a response, e.g. questions, it may also convey to the community that the raters are as well interested in the responds. Besides, rating may also act as an indicator of how many students are following the backchannel discourse.

Rating also servers to vote for posts to be forwarded to the lecturer. Since the lecturer can only pay little attention to the backchannel she might rely on social filtering in order to be provided with a distilled selection of the thoughts and comments shared on the backchannel that the audience finds especially relevant. Rating serves as a means to social filtering of the backchannel as the posts voted for by a sufficient number of students are shown at the lecturer's dashboard. 


\section{4) Annotation of Slides}

As mentioned in Section III the backchannel posts are used to annotate slides by an iconic drag-and-drop approach. Leaving aside the aspect of guidance, the location of posts provides useful awareness information to both students and lecturer. A slide annotation conveys two kinds of information: the location at the slide that establishes a reference to the topics presented at the slide, and the post category hinting at the content of the post. Annotations allows others to quickly find out if a post is likely to be of interest without the need to reading the post. Similar to the categorical distribution of posts presented above, the annotation of slides provides a topical distribution of posts according to the topics presented at the slides. For example, the lecturer can easily find out which parts of the slides gave rise to many questions. She can also recognize a lack of questions despite being expected, hinting at students who do not properly follow the lecture, neither on the backchannel nor on the frontchannel. However, in both cases the lecturer has the opportunity to step in, for example, by conducting a quiz related to the topic at hand.

5) Filter Boxes to Increase the Lecturer's Awareness of the Backchannel

As mentioned in Section IV.3 the lecturer can also be provided with a ranking of posts referring to the current slide on the basis of the students' votes. Yet, leaving aside social filtering of the backchannel discourse, the lecturer has no means to restrict the backchannel discourse according to the needs at hand. For example, during the presentation of a difficult proof she might want to be provided with just the posts that are critical for the understanding of the proof. Instead of obtaining a ranking of all posts referring to the current slide, she might solely be provided with a ranking of questions. Alternatively, she might be interested in all posts of "low-average" students in order to support them. Providing the capabilities to express such filter criteria helps the lecturer to obtain the kind of awareness information particularly needed in certain phases of the lecture.

For this reason we propose to integrate message filters into Backstage. Those filters may account for content-related parameters (e.g. keywords or tags contained, length of posts, certain categories of posts), or quality-related parameters (rating of posts to obtain a ranking, or the reputations of authors used as an a-priori estimate of quality).

As suggested above, message filters affect the posts that refer to the current slide. Thus, one can consider the filtering of posts as a cascade of two filters: the current slide that filters for currently relevant candidate posts and the message filter that processes the candidate posts returned by the slide. However, one could question if the filtering of the backchannel by slides is always sufficient. In the example above, the proof might be rather short and take up just a part of the slide. In order to be provided with only the posts that refer to the proof the lecturer should be able to restrict the backchannel discourse to the candidate posts that are placed nearby. The filtering works in much the same way as filtering by slides.

We therefore suggest generalizing the filtering of posts by slides to filtering of posts using location filters, or simply boxes. Each slide can then be considered as a box. However, a box may also comprise only a part of a slide. In the example above, the lecturer could draw, i.e. specify, a box around the proof. The selection of that box leads to a filtering for posts located nearby the proof.

We consider the box to be named by the lecturer using a meaningful label. In the example, the teacher might label the box with "proof of theorem X". Labelling boxes that way allows us to carry forward the concept: boxes may also comprise several slides. The grouping is thereby accomplished by providing the same label to each of the slide. Boxes can thus be used to filter the backchannel discourse also at a more coarse level. In the example above, imagine that the theorem and its proof take up several subsequent slides. During the presentation of the proof the lecturer could be provided with all questions that refer to the theorem as well as the complete proof, i.e. all posts that belong to the group of slides.

As the example illustrates, the combination of message filters and boxes can be quite useful for the lecturer, since it enables her to become aware of the actual relevant backchannel posts. The restriction of the backchannel discourse may, but does not need to, rely on social filtering by the audience. While the message filter is used to restrict the kinds of posts to be displayed the boxes account for meaningful references to the lecture discourse that is comprised by groups of slides, single slides, or specific areas on slides.

The filter box approach only works well as long as the students place posts properly, i.e. associate the posts to the locations at the slides they actually refer to. The approach can thus be seen as an instance of reciprocal actions in Backstage: Students have to properly annotate slides in order to enable filter boxes to provide meaningful results to the lecturer. Conversely, the students gain the most attention of their peers and the lecturer by properly positioning her posts at the slides. Furthermore, if the label of the box is more elaborate (e.g. "proof of perron's theorem", rather than simply "theorem"), the label can be attached to any post located inside the box. This facilitates the construction of a topical catalogue, a table of contents of the backchannel discourse, provided by the lecture, which allows for a topical indexing of the backchannel discourse.

In most cases it can be assumed that the creation of boxes follows the logical structure of the presentation slides, e.g. sections or special paragraphs such as "theorem" or "proof". In the current version of Backstage, however, the slides are transformed (from PDF) to mere graphics, which enables us to use standard HTML for the display of slides. As a consequence, the creation of location filters cannot rely on meta-information such as the logical structure of the presentation slides. At the very latest, such information goes astray during the transformation. As a consequence, the location filters would have to be created manually in a separate processing step. While in this way the lecturer has the opportunity to reflect on the parts of the slide that might be difficult for the students, a more practical solution might be required in versions of Backstage that are targeted at the deployment for public use. 


\section{CONCLUSION AND FUTURE WORK}

In this paper we present several concepts by which we aim to provide information that may contribute to improving the awareness of the activities during the lecture. We focused on two kinds of awareness information: social awareness information relates to the involvement of users in the backchannel and the lecture, and workspace awareness information relates to the communication that takes place on the backchannel. We reviewed existing functionalities of Backstage in the light of how they contribute awareness information and presented further concepts, such as the Activity Aggregator and Filter Boxes that we plan to realize.

We are aware of the fact that the mere provision of awareness information does not per se result in an improvement of awareness of classroom activities (cf. [16]). Certainly, the concepts need to be evaluated in their usefulness as perceived by the users of Backstage, which requires research in the laboratory and in the field.

Besides the dependency to the progress of the lecture, awareness information needs to be regularly updated. While some pieces of information can be updated at the time they are explicitly requested, e.g. the presence of a user in Backstage, other pieces of information need to be updated continuously, e.g. the data displayed by the Activity Aggregator. In [25] we discussed how actuality can be discerned in Backstage and proposed to use the activity on the backchannel as a measure of time as it may reflect "progress" of a lecture more suitably. Thus it makes sense to also update the data in accordance to the activity in Backstage, i.e. to integrate the awareness components with the activity-based timer on Backstage.

Though the concept of filter boxes bears challenges regarding the usability for the lecturer, they are a promising way to realize a concise user interface of Backstage for smallscreen mobile devices. The interactions on Backstage rely on the slides to a great extent, which however is quite inconvenient for small devices such as smart phones. The filter boxes provide means to design the interactions without the need to explicitly rely on the graphical representation of the slides. We will report on this topic in a forthcoming paper.

\section{REFERENCES}

[1] W.A. Kellogg, T. Erickson, T.V. Wolf, S. Levy, J. Christensen, J. Sussman, and W.E. Bennet, "Leveraging Digital Backchannels to Enhance User Experience in Electronically Mediated Communication," Proceedings of 20th Anniversary Conference on Computer Supported Cooperative Work, 2006.

[2] N. Saunders, P. Beltrao, L. Jensen, D. Jurczak, R. Krause, M. Kuhn, and S. Wu, "Microblogging the ISMB: A New Approach to Conference Reporting," PLoS Computational Biology, vol. 5, 2009.

[3] J.F. McCarthy and D.M. Boyd, "Digital Backchannels in Shared Physical Spaces: Experiences at an Academic Conference," In Extended Abstracts, Human Factors in Computing Systems (CHI 2005); $A C M$, Press, 2004, pp. 550-553.

[4] S. Yardi, "The Role of the Backchannel in Collaborative Learning Environments," ICLS '06: Proceedings of the 7th International Conference on Learning Sciences, International Society of the Learning Sciences, 2006, pp. 852-858.

[5] M. Ebner and M. Schiefner, "Microblogging -- More than Fun?," Proceeding of IADIS Mobile Learning Conference 2008, S. Immaculada Arnedillo and P. Isaias, eds., 2008, pp. 155-159.
[6] M. Ebner, "Is Twitter a Tool for Mass-Education?," Proccedings of the 4th International Conference on Student Mobility and ICT, Vienna: 2011

[7] A.S.C. Leh, "Computer-Mediated Communication and Social Presence in a Distance Learning Environment.," International Journal of Educational Telecommunications, vol. 7, 2001, pp. 109-28.

[8] P. Dourish and V. Bellotti, "Awareness and Coordination in Shared Workspaces," Proceedings of the 1992 ACM Conference on Computer-Supported Cooperative Work, New York, NY, USA: ACM, 1992, pp. $107-114$

[9] F. Bry, V. Gehlen-Baum, and A. Pohl, "Promoting Awareness and Participation in Large Class Lectures: the Digital Backchannel Backstage," Proceedings of the IADIS International Conference esociety, Spain, Avila: 2011, pp. 27-34.

[10] A. Pohl, V. Gehlen-Baum, and F. Bry, "Introducing Backstage -- A Digital Backchannel for Large Class Lectures," Interactive Technology and Smart Education, vol. 8, 2011, pp. 186-200.

[11] V. Gehlen-Baum, A. Pohl, and F. Bry, "Assessing Backstage -- A Backchannel for Collaborative Learning in Large Classes," Proceedings of the International Conference ICL 2011, Slovakia: 2011, pp. 154-160.

[12] T.W. Malone, K.R. Grant, and F.A. Turbak, "The Information Lens: An Intelligent System for Information Sharing in Organizations," SIGCHI Bulletin, vol. 17, Apr. 1986, pp. 1-8.

[13] P. Dourish and S. Bly, "Portholes: Supporting Awareness in a Distributed Work Group," Proceedings of the SIGCHI Conference on Human Factors in Computing Systems, New York, NY, USA: ACM, 1992 , pp. $541-547$

[14] M. Rittenbruch and G. McEwan, "An Historical Reflection of Awareness in Collaboration," Awareness Systems, P. Markopoulos, W. Mackay, and B. Ruyter, eds., Springer London, 2009, pp. 3-48.

[15] M. Rittenbruch, T. Mansfield, and S. Viller, "Design and Evaluation of Intentionally Enriched Awareness," Awareness Systems, P. Markopoulos, B. De Ruyter, and W. Mackay, eds., Springer London, 2009, pp. 367-395.

[16] K. Schmidt, "The Problem with 'Awareness': Introductory Remarks on 'Awareness in CSCW'," Computer Supported Cooperative Work, vol. 11, Nov. 2002, pp. 285-298.

[17] N. Lambropoulos, X. Faulkner, and F. Culwin, "Supporting Social Awareness in Collaborative E-Learning," British Journal of Educational Technology, vol. 43, 2012, pp. 295-306.

[18] C. Gutwin, G. Stark, and S. Greenberg, "Support for Workspace Awareness in Educational Groupware," The First International Conference on Computer Support for Collaborative Learning, Hillsdale, NJ, USA: L. Erlbaum Associates Inc., 1995, pp. 147-156.

[19] D. Baumgart, A. Pohl, V. Gehlen-Baum, and F. Bry, "Providing Guidance on Backstage, a Novel Digital Backchannel for Large Class Teaching," Education in a Technological World: Communicating Current and Emerging Research and Technological Efforts, Spain: Formatex, 2012, pp. 364-371.

[20] R.H. Kay and A. LeSage, "Examining the Benefits and Challenges of using Audience Response Systems: A Review of the Literature," Computers \& Education, vol. 53, 2009, pp. 819 - 827 .

[21] C. Fies and J. Marshall, "Classroom Response Systems: A Review of the Literature," Journal of Science Education and Technology, vol. 15, 2006, pp. 101-109.

[22] R.W. Preszler, A. Dawe, C.B. Shuster, and M. Shuster, "Assessment of the Effects of Student Response Systems on Student Learning and Attitudes over a Broad Range of Biology Courses," CBE Life Science Education, vol. 6, 2007, pp. 29-41.

[23] E. Mazur, "Farewell, Lecture?," Science, vol. 323, Jan. 2009, pp. 50 51.

[24] E. Ostrom, "A Behavioral Approach to the Rational Choice Theory of Collective Action: Presidential Address, American Political Science Association, 1997," The American Political Science Review, vol. 92, Mar. 1998, pp. 1-22.

[25] J. Hadersberger, A. Pohl, and F. Bry, "Discerning Actuality in Backstage -- Comprehensible Contextual Aging," Proceedings of the 7th European Conference on Technology Enhanced Learning, Saarbrücken, Germany: Springer, submitted. 